\title{
Total Repair Cost Simulation Considering Multiple Probabilistic Measures and Service Life
}

\author{
Yong-Sik Yoon ${ }^{1}$, Yong-Han Ahn ${ }^{2}$, Xiao-Yong Wang ${ }^{3,4}$ (D) and Seung-Jun Kwon ${ }^{1, *(D)}$ \\ 1 Department of Civil and Environmental Engineering, Hannam University, 70 Hannam-ro, \\ Daedeok-gu, Daejeon 34430, Korea; humbleyys@gmail.com \\ 2 Department of Architectural Engineering, Hanyang University ERICA, 55 Hanyangdaehak-ro, \\ Sangrok-gu, Ansan 15588, Korea; yhahn@hanyang.ac.kr \\ 3 Department of Architectural Engineering, Kangwon National University, 1 Kangwondaekah-gil, \\ Chuncheon 24341, Korea; wxbrave@kangwon.ac.kr \\ 4 Department of Intergrated Energy and Infra System, Kangwon National University, \\ 1 Kangwondaekah-gil, Chuncheon 24341, Korea \\ * Correspondence: jjuni98@hannam.ac.kr
}

Citation: Yoon, Y.-S.; Ahn, Y.-H.; Wang, X.-Y.; Kwon, S.-J. Total Repair Cost Simulation Considering Multiple Probabilistic Measures and Service Life. Sustainability 2021, 13, 2350. https://doi.org/10.3390/ su13042350

Academic Editor: Sungkon Moon

Received: 18 January 2021

Accepted: 18 February 2021

Published: 22 February 2021

Publisher's Note: MDPI stays neutral with regard to jurisdictional claims in published maps and institutional affiliations.

Copyright: (c) 2021 by the authors. Licensee MDPI, Basel, Switzerland. This article is an open access article distributed under the terms and conditions of the Creative Commons Attribution (CC BY) license (https:/ / creativecommons.org/licenses/by/ $4.0 /)$.

\begin{abstract}
In this study, the total maintenance cost for public houses in South Korea was analyzed, and the effect of each repair process on the total maintenance cost was evaluated with probabilistic and deterministic methods. In the probabilistic method, quality of repair materials and construction skills were considered in the variability of extended service life through repair, while the deterministic method considered it by simple summation of repair step. The repair cost was analyzed considering the coefficient of variation (COV) of extended service life, so the reasonable total maintenance cost was able to be evaluated. Since the results through the probabilistic method provided a continuous cost line, a reasonable repair strategy was carried out by simply changing the intended service life of the structure. The repair cost was additionally analyzed with constant COV (0.15) of each repair process for considering various situations. The analysis results with a COV of 0.15 exhibited a slightly higher maintenance cost than those with current COV. The total maintenance costs can be adjusted if the initial repair timing is extended to the largest possible extent for the highest-repair-cost process since the total repair cost is dominated by the process with the highest repair cost.
\end{abstract}

Keywords: repair cost; service life; probabilistic method; deterministic method; COV

\section{Introduction}

For large structures, the exposure environment is analyzed, and thereafter, the durability design is established based on deterioration modeling to secure stability and durability [1,2]. The target service life and remaining life of a structure are evaluated from an engineering perspective; however, the maintenance cost of a typical building structure continuously increases by being used. Because the expected lifespan is different for each member, the stepwise maintenance cost is considered an important factor for long-term maintenance measures [3]. For rental housing, the importance of long-term maintenance planning is being acknowledged because the damage is different for each member and the deterioration process owing to the different lifestyles of the users [4].

As the importance of service life and effective maintenance costs are being recognized, various studies have been conducted for predicting the service life of building structures. However, these studies are mainly focused on the evaluation for a specific time period and do not consider the entire life cycle [5-7]. Generally, the deterministic methods have been used in these studies; accordingly, the maintenance cost of a structure or member is determined by simply totaling the additional costs. Such deterministic methods or probabilistic methods applied in modeling have been used to evaluate the service life or repair period of large structures as well as the service life of rental houses $[8,9]$. 
Many studies have been conducted to reduce the risk caused by uncertainties in the construction of individual structural members. As representative cases, studies on building information modeling (BIM) and robot-based construction to improve the accuracy and efficiency of element construction and studies on virtual construction and lean construction have been conducted [10-13]. The main purpose of these studies, however, has been to mitigate the risks that occur in the construction stage, and few studies have been conducted to analyze the maintenance costs of the facilities considering the service life of each member. Considering the service life of the various members and analyzing the probabilistic behaviors are essential for the calculation of user satisfaction and maintenance costs $[3,14]$. Recently, studies have been conducted to systematize the members for the finishing work of rental houses and to analyze the pattern of service life for each repair process through probabilistic approaches [14]. While these studies are considerably effective in constructing databases for maintenance by analyzing the service life variation of each member, they face limitations in the calculation of the total maintenance cost considering the service life.

The probabilistic maintenance technique considers the effects of repair timing and repair cost on each process [15-18]. Techniques for probabilistic repair cost calculation based on engineering modeling have been proposed recently; however, the probabilistic variation of the service life considering the initial service life and repair is limited to a normal distribution, and such techniques are limited to only the service life [1,19-21]. An analysis technique has also been developed considering the influence of the mean and standard deviation of the service life spanning across various initial service lives and repairs, under the assumption of a normal distribution [22]; however, only a few studies have actually considered the repair costs and probabilistic measures of the evaluated members.

In this study, the measured repair and maintenance costs of the representative repair processes for public houses in South Korea were analyzed. In addition, the total maintenance cost resulting from the extension of the service life was analyzed using deterministic and probabilistic methods. Further, the effects of the probabilistic variation and repair cost for each repair process on the total maintenance cost were quantitatively analyzed.

\section{Literature Review on Probabilistic Service Life Analysis and Repair Process Probabilistic Measures}

\subsection{Probabilistic Process-Based Member Probability Distribution Evaluation Technique}

In previous studies, frequency distribution was determined through morphological fitting to derive the frequency distribution of each process, and this was applied to Equation (1) to perform a Monte Carlo simulation: [3,14]

$$
S L C_{n}=\frac{\sum\left(F C_{(t, n)} \times P_{t}\right)}{\sum F C_{(t, n)}}
$$

where $S L C_{n}$ is the service lifetime of the component, $F C_{(t, n)}$ is the frequency distribution of the component, and $P_{t}$ is the time period.

Equation (1) is used to obtain the weighted average of the frequency corresponding to each time point of the finishing work member, and the service life is set based on this equation. This method has an advantage over the existing method for calculating service life because, rather than simply entering the average of service life, it can consider uncertainty by the Monte Carlo Simulation. The derived frequency distribution is entered, and a Monte Carlo simulation is performed to consider uncertainty. After this, mean and standard variation is derived. Figure 1 shows the procedure for constructing the probability distribution based on each process after constructing the service life matrix of each finishing work member $[3,14]$. The considering of skewness of distribution is efficient for the centralization of repair processes. For processes such as finishing materials, the classifications and considerations have been analyzed appropriately in the previous studies [23,24]. 


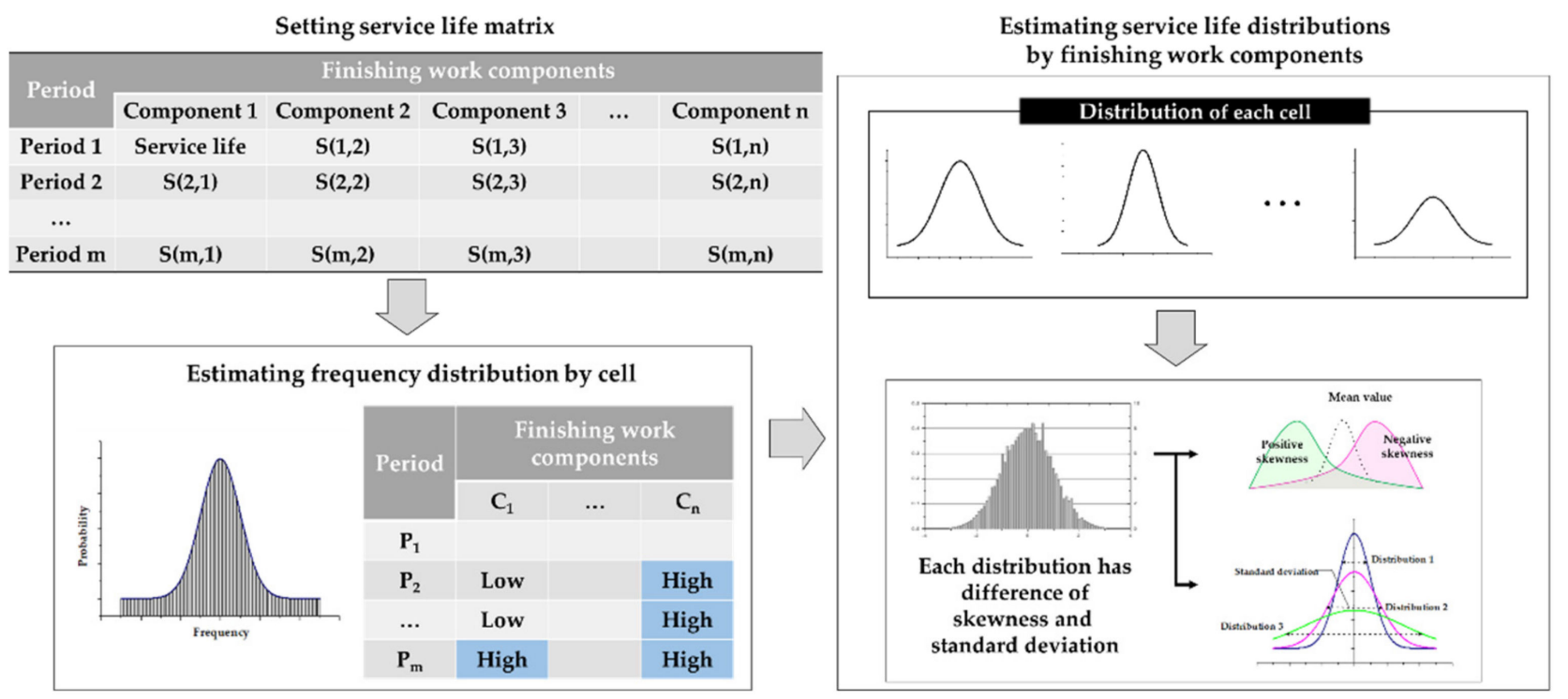

Figure 1. Schematic diagram of service life pattern analysis.

\subsection{Probabilistic Repair Cost Calculation Technique}

In the previous studies on probabilistic repair timing and cost, the repair cost was evaluated considering the period for which no maintenance was required (maintenancefree period) $\left(T_{1}\right), N$-th repair timing $\left(T_{N}\right)$ and the coefficient of variation (COV) of the secured service life $[20,25]$. For the maintenance-free period, the number of repairs is zero, and the boundary condition can be defined as shown in Equation (2).

$$
T_{1} \geq T_{\text {end }}
$$

where $T_{1}$ is the first repair timing and $T_{\text {end }}$ is the target service life.

If $\overline{T_{1}}$ is defined as the average value of the first repair timing, the standardized variable $(\beta)$ and the maintenance-free probability $\left(P_{1}\right)$ can be expressed as Equations (3) and $(4)[19,20]$.

$$
\begin{gathered}
\beta=\frac{T_{\text {end }}-\overline{T_{1}}}{\sigma_{1}} \\
P_{1}=\int_{\beta_{1}}^{\infty} \frac{1}{\sqrt{2 \pi}} \exp \left(-\frac{\beta^{2}}{2}\right) d \beta
\end{gathered}
$$

where, $\sigma_{1}$ is the standard deviation of $\overline{T_{1}}$ at the first repair timing.

The conditions to ensure that the number of repairs is one are: $T_{1}$ is smaller than the target service life $\left(T_{\text {end }}\right)$ and the sum of $T_{2}$ and $T_{1}$ is larger than $T_{\text {end }}$. In this case, the standardized variable can be expressed by Equation (5). In addition, the probability $\left(P_{2}^{*}\right)$ that the sum of $T_{1}$ and $T_{2}$ is larger than $\overline{T_{1}}$, can be expressed as Equation (6) [20,25]:

$$
\begin{gathered}
\beta=\frac{\left[\left(T_{\text {end }}-\left(\overline{T_{1}}+\overline{T_{2}}\right)\right]\right.}{\sqrt{\sigma_{1}^{2}+\sigma_{2}^{2}}} \\
P_{2}{ }^{*}=1-\int_{-\infty}^{\beta_{2}} f(\beta) d \beta=\int_{\beta_{2}}^{\infty} f(\beta) d \beta, \text { and } \\
P_{2}{ }^{*}=\int_{\beta_{2}}^{\infty} \frac{1}{\sqrt{2 \pi}} \exp \left(-\frac{\beta^{2}}{2}\right) d \beta
\end{gathered}
$$


where $\sigma_{i}$ is the standard deviation of $T_{i}$. The probability of failure when the number of repairs is one $\left(P_{2}\right)$ can be expressed as Equation (7). In addition, the probability of failure for $n$ repairs can be expressed by Equation (8):

$$
\begin{gathered}
P_{2}=\left(1-P_{1}\right) \times P_{2}^{*} \\
P_{n}=\left(1-\sum_{k=1}^{n-1} P_{k}\right) \times P_{n}^{*}
\end{gathered}
$$

Figure 2 shows the concept of the probability-based repair timing derivation and maintenance probability covered in Section 2.2. The probability of failure for $n\left(P_{n}\right)$ is evaluated through repetition of the procedure in Figure 2.
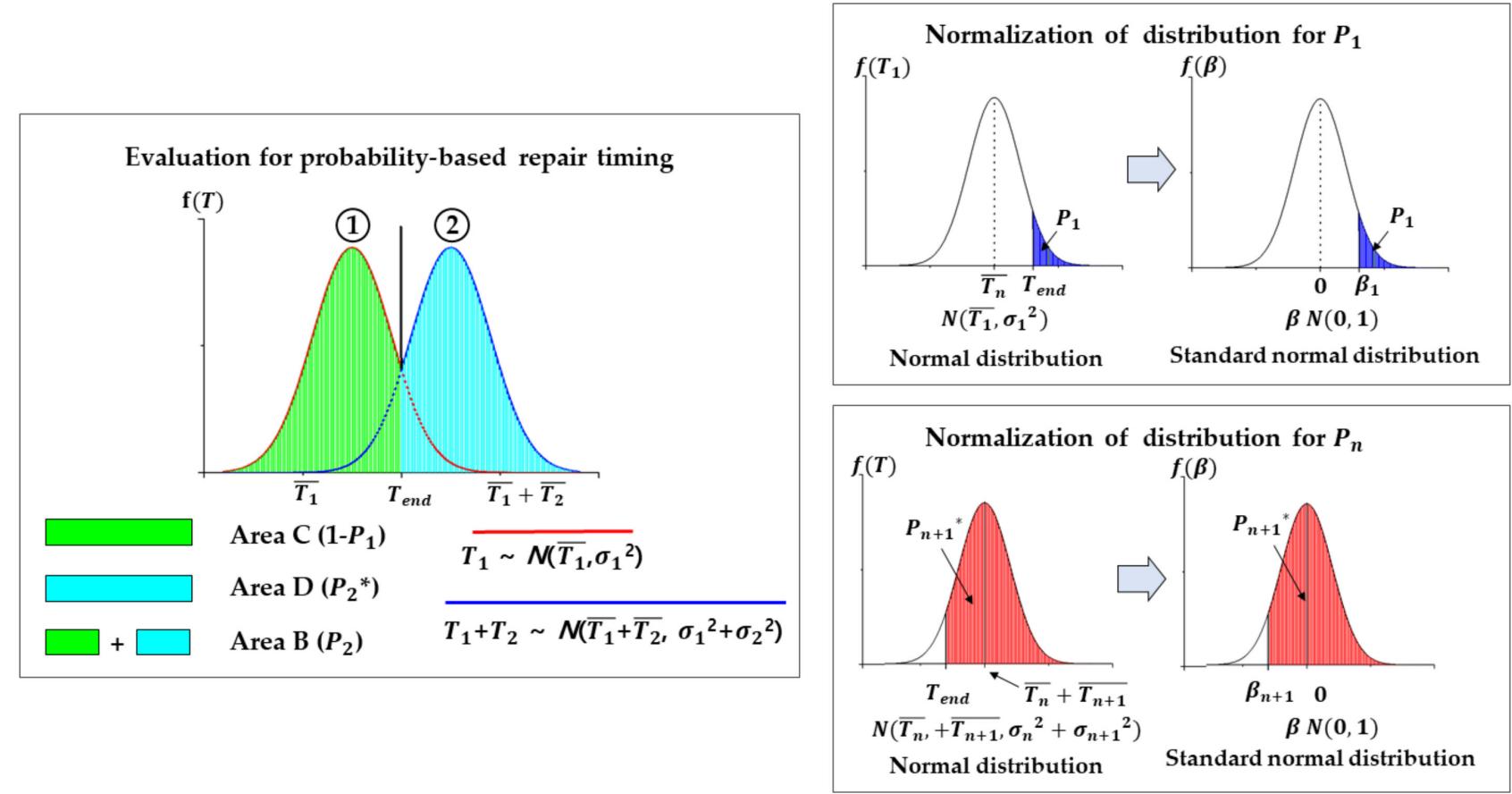

Figure 2. Schematic diagram of probability-based repair timing evaluation $[19,20]$.

\section{Determination of Service Life Distribution of Each Repair Process}

\subsection{Determination of Probability Distribution for Each Member}

The service life probability distributions for each repair process derived in a previous study [14] are summarized in Table 1. These distributions were derived from the results of the factual survey for repair processes in the process as in Section 2.1. The collected data were 46,201 maintenance cases for 41 buildings in six public housing complexes in Seoul, South Korea, for 21 years from 1997 to 2017 . The public houses under investigation were aged 25 years or older [14]. They can be expressed along the same time-axis, as shown in Figure 3. All of them exhibited a normal distribution with a service life between 14.80 and 20.18 years and a COV value between 1.8 and $13.8 \%$. The COV was very low compared with the service life setting of the general structures. This is because construction-related works, such as demolition and extensive repairs, are performed at planned time points. 
Table 1. Statistics of service life distributions.

\begin{tabular}{cccccc}
\hline \multirow{2}{*}{ Serial No. } & Finishing Work & \multicolumn{3}{c}{ Statistics of Service Life Distributions } \\
\cline { 3 - 5 } & Member & Mean & Median & Mode & COV \\
\hline 1 & Painting work & 16.57 & 16.57 & 16.25 & 0.028 \\
2 & Plaster work & 19.14 & 19.20 & 19.75 & 0.058 \\
3 & Water proof work & 18.94 & 18.94 & 18.91 & 0.027 \\
4 & Interior finishing & 14.80 & 14.79 & 14.80 & 0.018 \\
5 & Tile work & 16.08 & 16.08 & 16.21 & 0.028 \\
6 & Carpentry work & 16.29 & 16.33 & 17.37 & 0.138 \\
7 & Doors and window & 16.41 & 16.41 & 16.17 & 0.020 \\
8 & Roof and drain & 20.18 & 20.23 & 20.23 & 0.058 \\
\hline
\end{tabular}

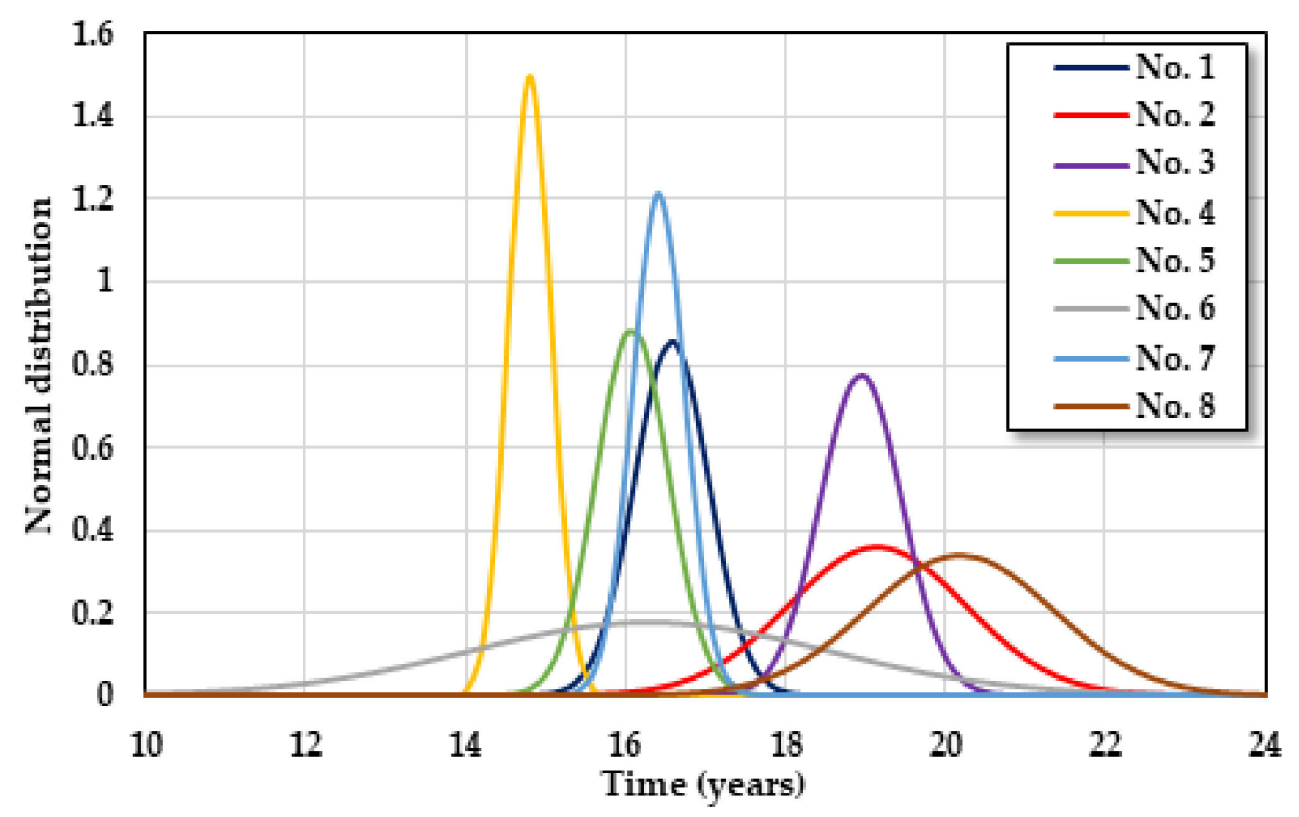

Figure 3. Probabilistic distributions of the member repair process.

\subsection{Investigation of Repair Cost Each Member Process}

Changes in repair cost depending on the period of use can be analyzed by considering the repair cost per unit area for the eight processes cited in Section 3.1. Table 2 and Figure 4 show the repair cost for each process as of 2019, respectively. The doors and window finishing works exhibited the highest repair costs because workmanship, including various other processes, and materials were required.

Table 2. Repair cost for each repair process [26].

\begin{tabular}{cc}
\hline Finishing Work Components & Repair Cost $/ \mathbf{m}^{\mathbf{2}} \mathbf{( \$ )}$ \\
\hline Painting work & 7.57 \\
Plaster work & 5.37 \\
Water proof work & 9.69 \\
Interior finishing & 4.31 \\
Tile work & 25.12 \\
Carpentry work & 6.99 \\
Doors and window & 66.16 \\
Roof and drain & 28.53 \\
\hline
\end{tabular}




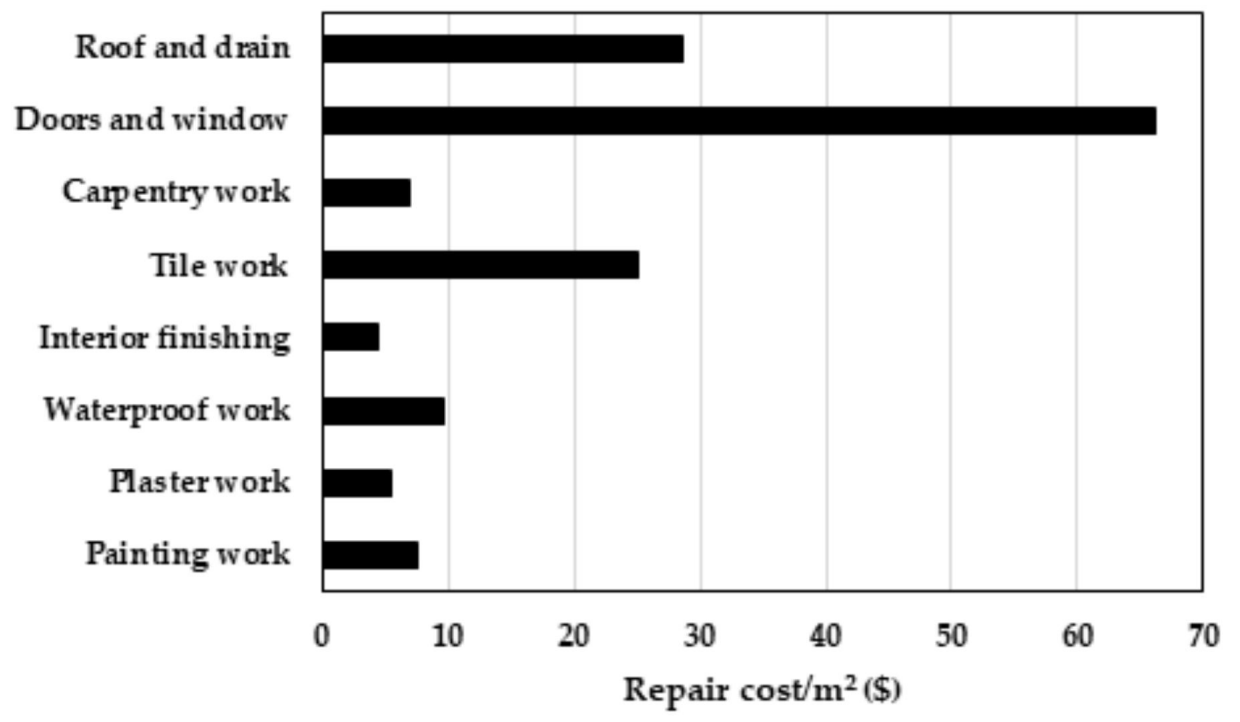

Figure 4. Repair cost for each repair work process.

4. Analysis of Maintenance Cost Based on the Repair Cost of Each Process and Evaluation of the Impact of Process Variation

4.1. Analysis of Maintenance Cost Based on the Evaluation Method for Each Process

Although there are differences depending on the process, it is known that the probabilistic evaluation method derived as a continuous function allows the effective evaluation of the repair cost, and it shows the same tendency as the deterministic method as COV decreases $[19,20,27]$. Figure 5 shows the repair cost calculation results for each process, and Figure 6 shows the repair cost ratio of the probabilistic method compared with that of the deterministic method when the target service life is assumed to be 60 years.

The frequency of each repair process within a given service life (60 years) was evaluated from two to four times. The repairing frequency was not the sole parameter that governed the total maintenance cost since the unit cost of each repair mainly affected the total maintenance cost. Interior finishing had not only the highest number of repairs (4 times) but also the second-lowest total repair cost among eight finishing work components for 60 years. The repair process of doors and windows had the highest repair cost per unit area, so it showed the highest total repair cost even if the number of repairs was only three times.

In the previous study [27], log and normal PSLF (probabilistic service life function) were considered, and the effect of initial and extended service life on repair cost was investigated with changing COV. The previous study handled PSLF type and patterns, but total repair cost was not evaluated. If the extended service life pattern from repairing can be experimentally obtained, which means mean, $\mathrm{COV}$, and pattern of service life, the probabilistic approach can be adopted more reasonably with a continuous cost line.

\subsection{Analysis of Maintenance Cost Based on the Service Life}

\subsubsection{When COV Is Low (Current Conditions)}

To analyze the maintenance cost with an increase in service life, the sum of repair costs over a particular time period is required. In the probabilistic method, it is calculated as a simple sum because the cost is expressed continuously over time. However, in the deterministic method, the cumulative sum according to the repair timing of each process must be considered in detail. Figure 7 shows the calculation equation for the total repair cost, and Figure 8 compares the repair costs obtained by the probabilistic and deterministic methods. Here, is the target service life, is the cost for each process throughout the period of use, is the repair cost for each process, is the service life in each process, and is the frequency of repair. 


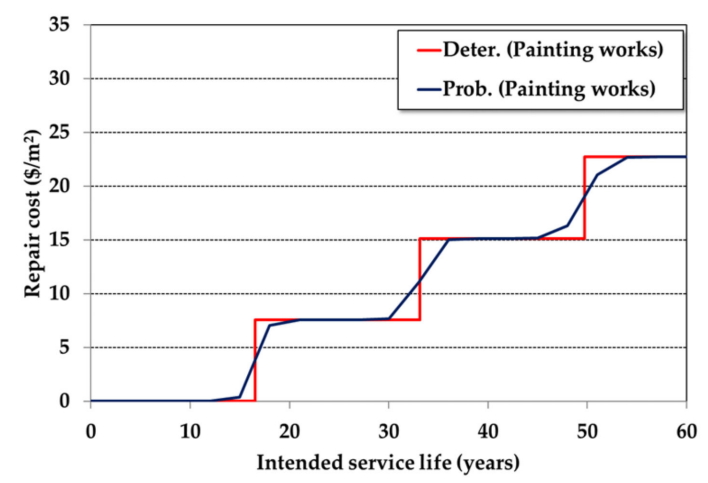

(a) Painting works

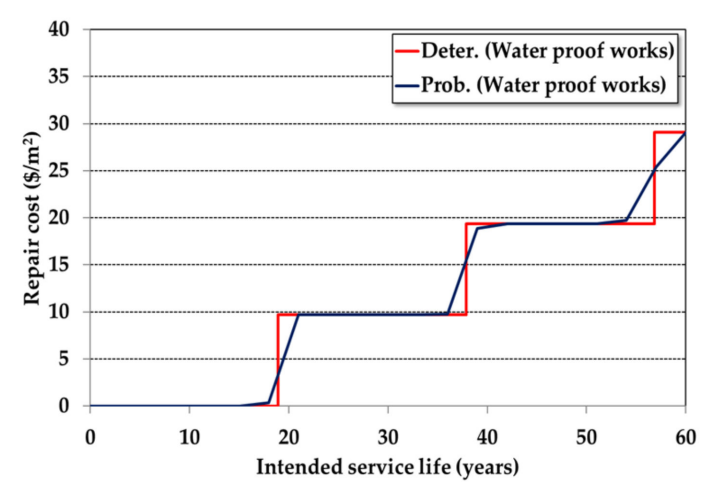

(c) Water proof works

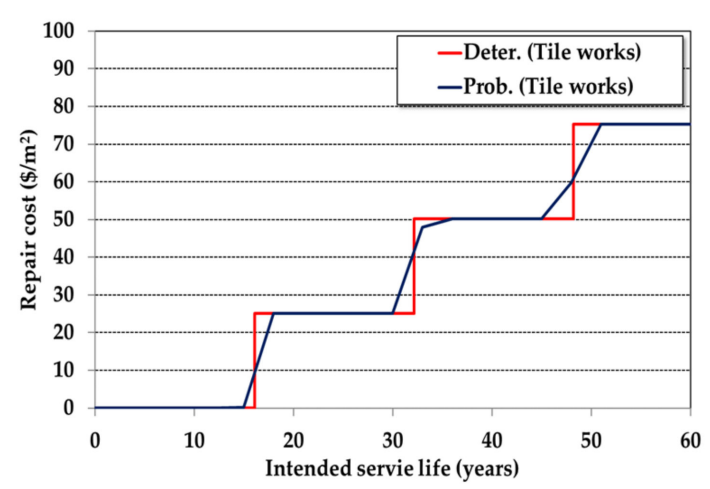

(e) Tile works

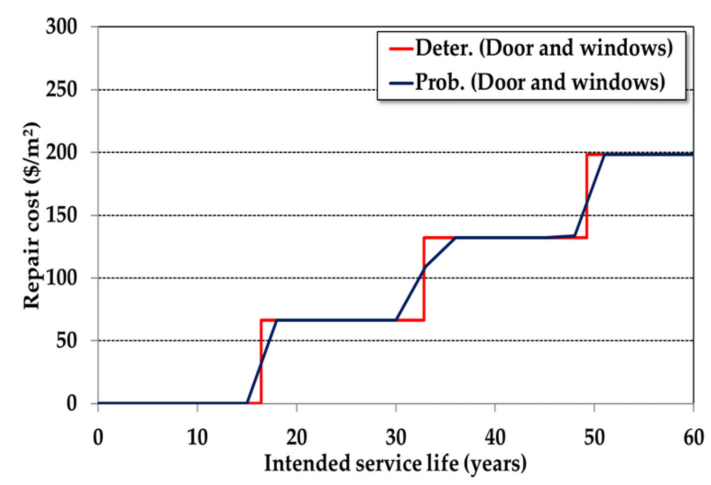

(g) Door and windows

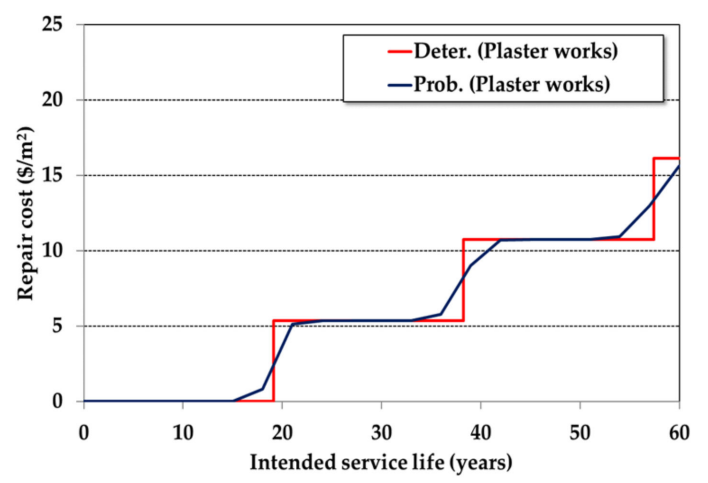

(b) Plaster works

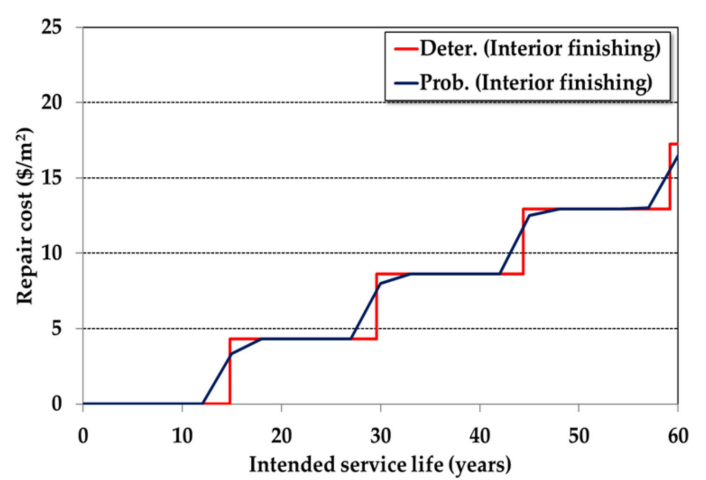

(d) Interior finishing

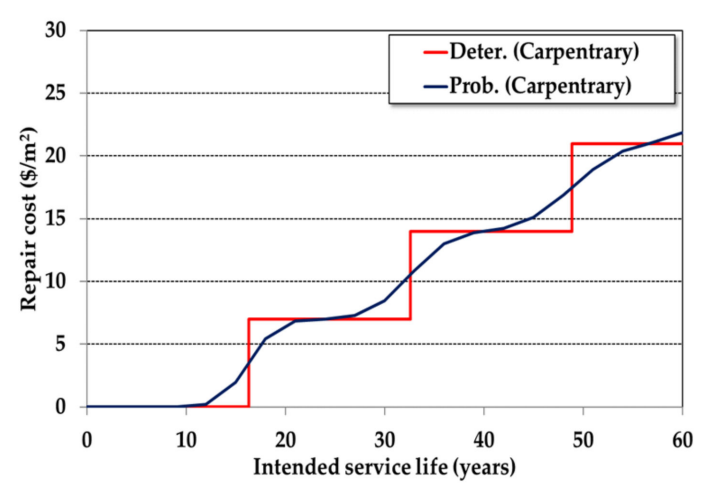

(f) Carpentry

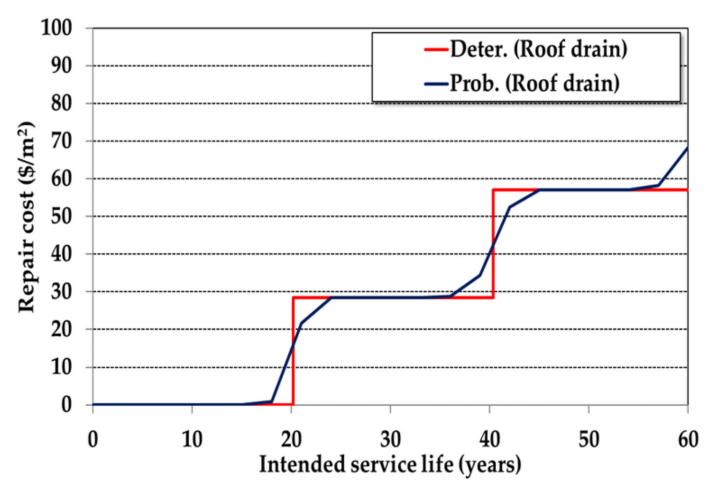

(h) Roof drain

Figure 5. Comparison of repair cost through deterministic and probabilistic methods. 


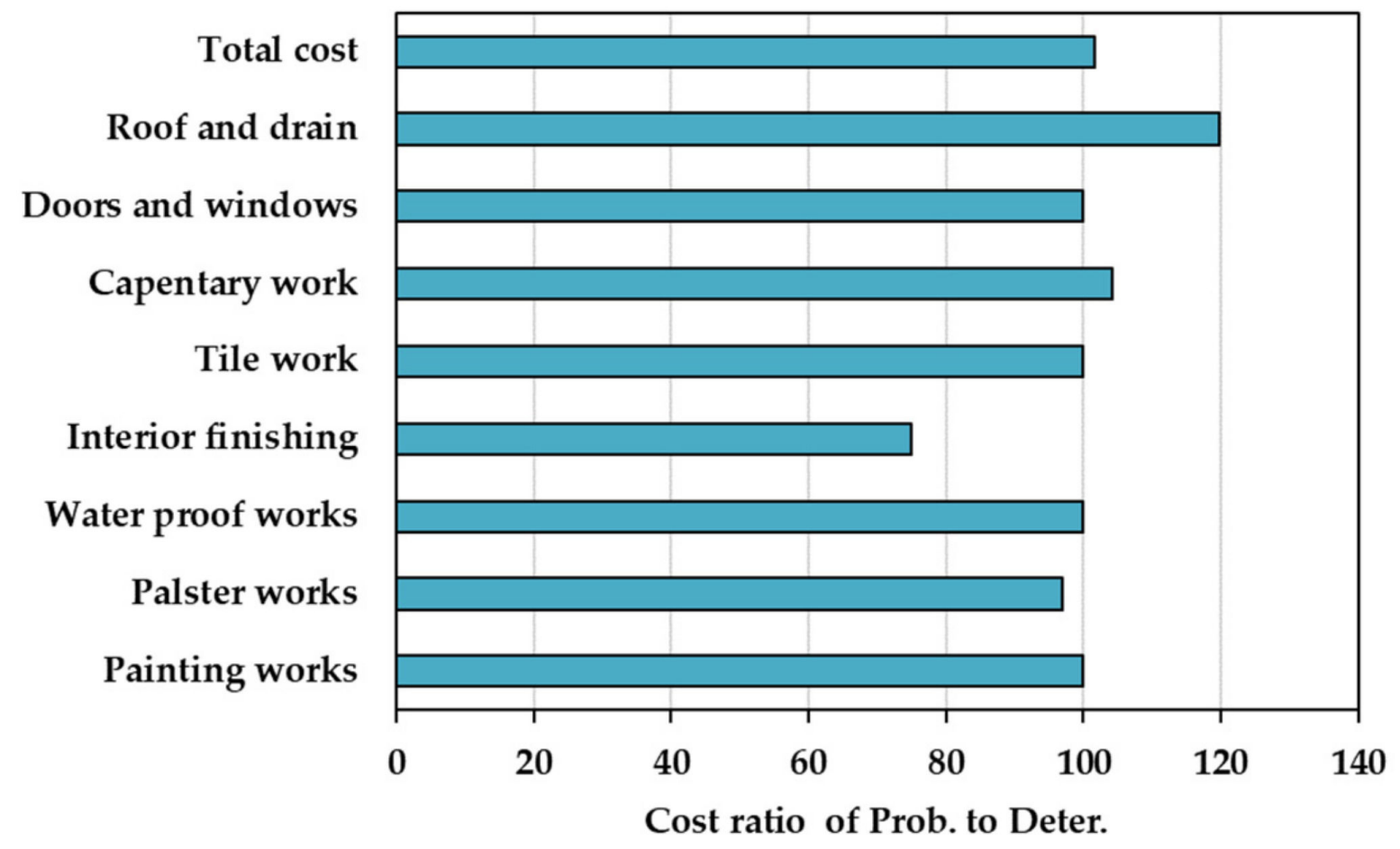

Figure 6. Repair cost ratio of the probabilistic method to deterministic method.

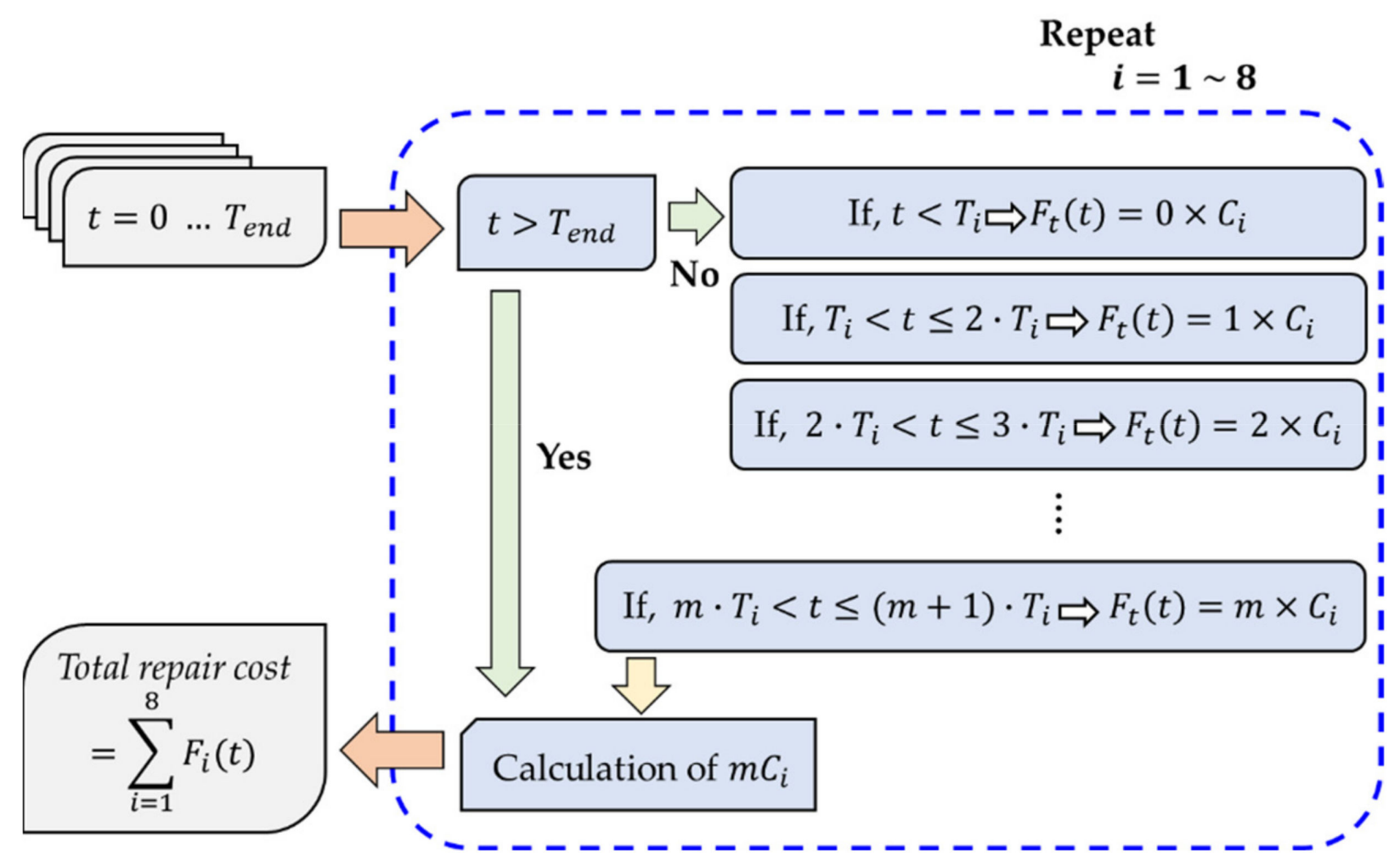

Figure 7. Calculation flowchart for total repair cost in deterministic method. 


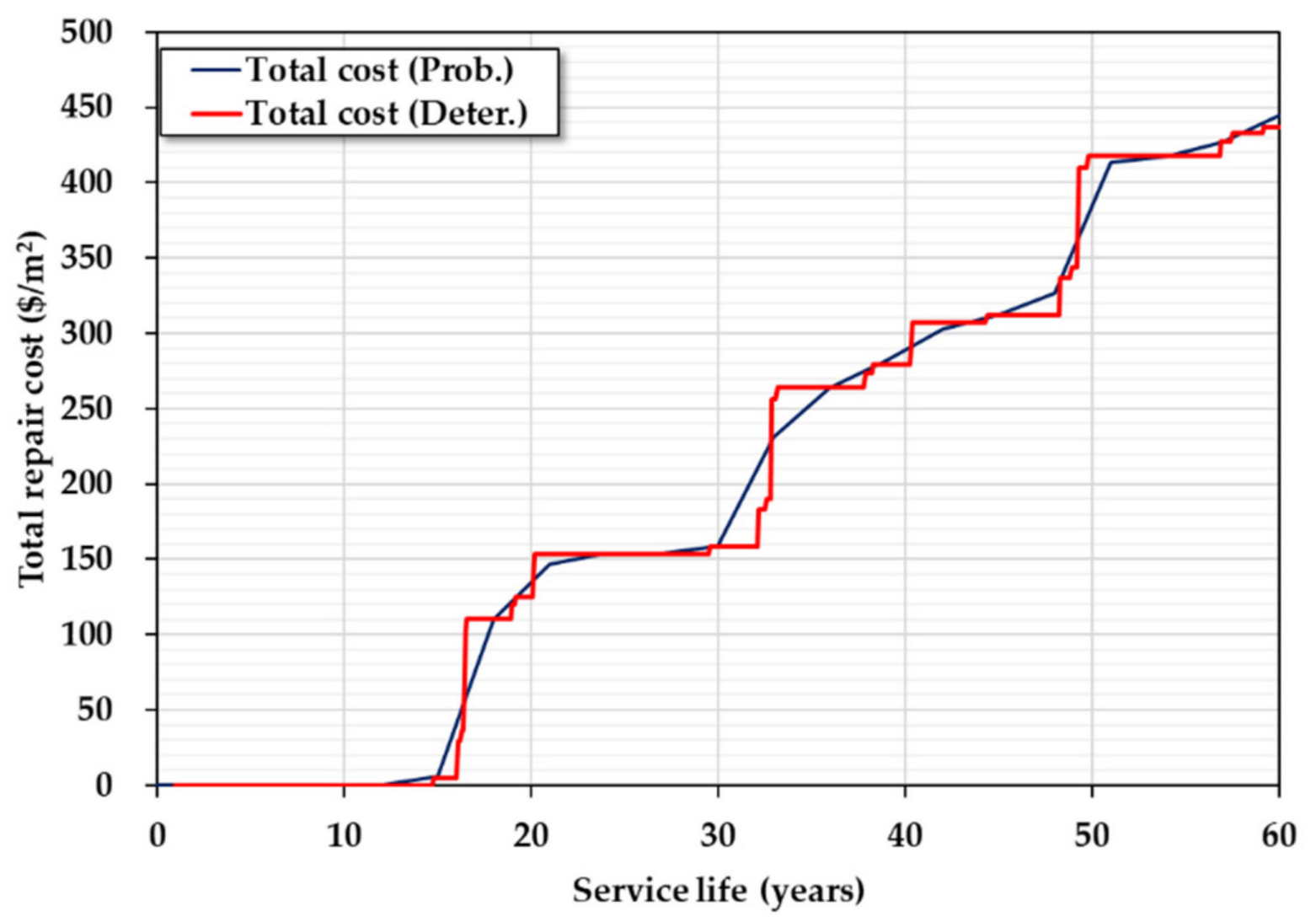

Figure 8. Total repair cost with different cost estimation methods.

As can be seen from Figure 8, there was no significant difference between the deterministic and probabilistic methods because the COV value for each process was very low (1.8-13.8\%). After 60 years, the total repair cost was evaluated to be $\$ 437$ for the deterministic method and $\$ 444$ for the probabilistic method. In the process with a high unit repair cost (door and window), the initial value of the repair cost increased significantly and impacted the total repair cost substantially.

\subsubsection{When COV Is Large (COV: 0.15)}

Significantly low COV values were evaluated (literature review in Section 3.1); however, the evaluation focused on cases in which the demolition and intensive repairs were performed at planned time points. Furthermore, the service life varies depending on the change in the lifestyle of users, quality of finishing and repair materials, or workmanship. In this section, changes in each repair cost and total repair cost were analyzed by assuming the service life variation of each process to be 0.15 . Figure 9 shows the changes in the probabilistic repair cost for each process. Figure 10 compares the changes in the total repair cost between the deterministic and probabilistic methods owing to the extended usage period. In addition, Figure 11 shows the sum of repair costs over 60 years for each process. It is known that the reasonable COV value ranges from 0.10 to 0.20 for structural engineering members $[19,20,25,27]$. 


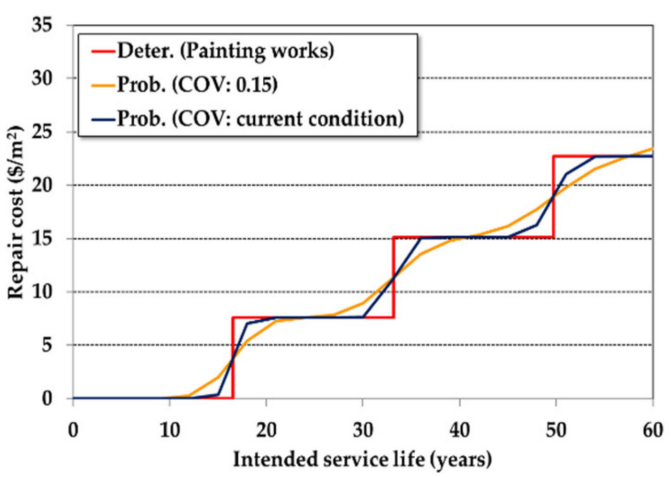

(a) Painting works

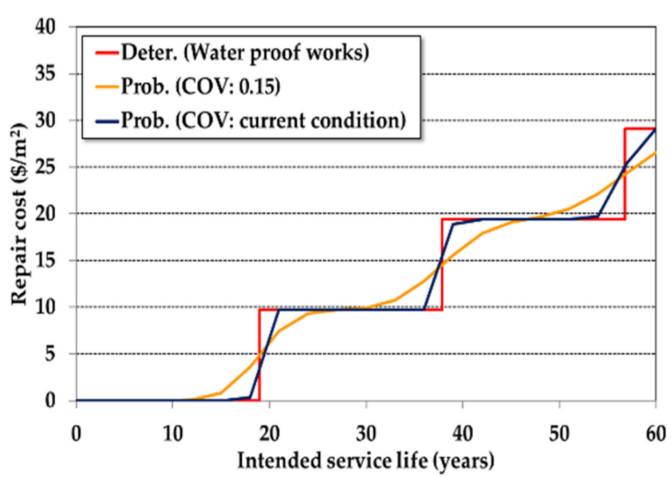

(c) Water proof works

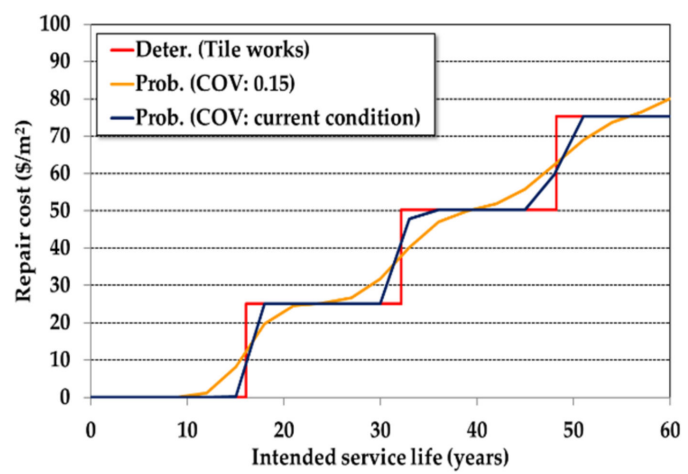

(e) Tile works

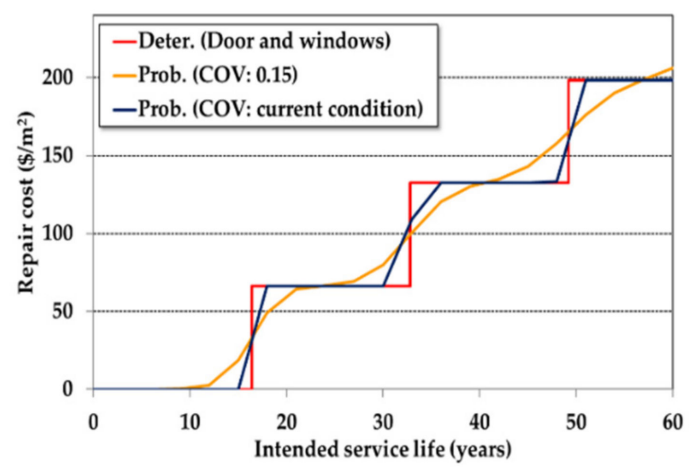

(g) Door and windows

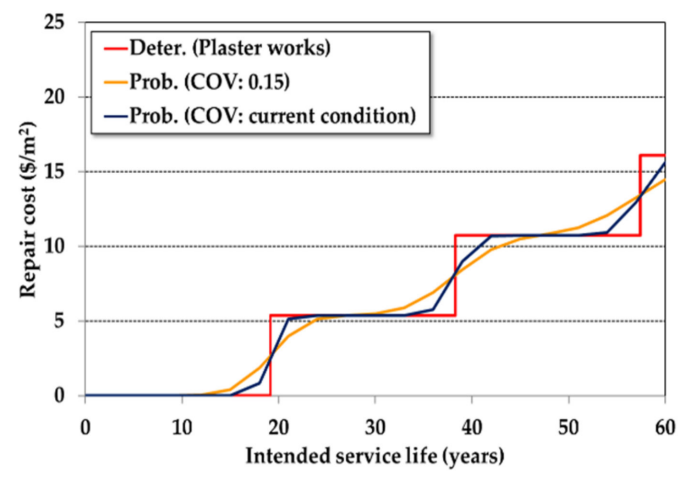

(b) Plaster works

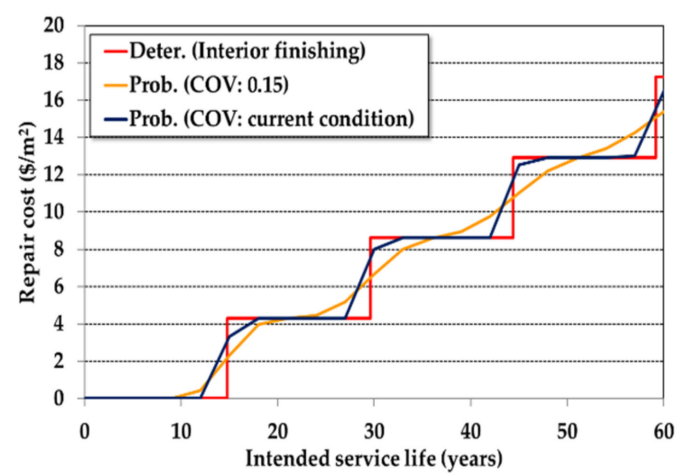

(d) Interior finishing

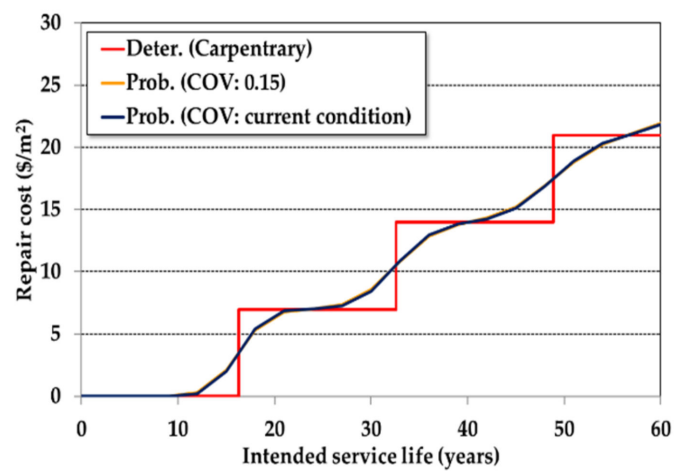

(f) Carpentry

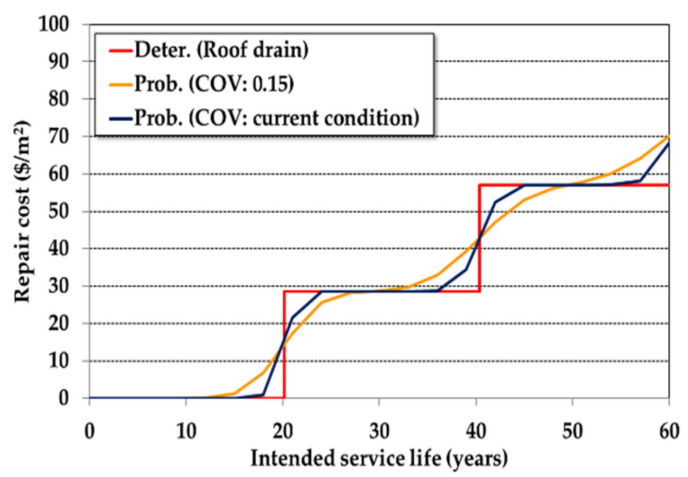

(h) Roof drain

Figure 9. Member repair cost based on deterministic and probabilistic methods (current and COV: 0.15) with extended service life. 


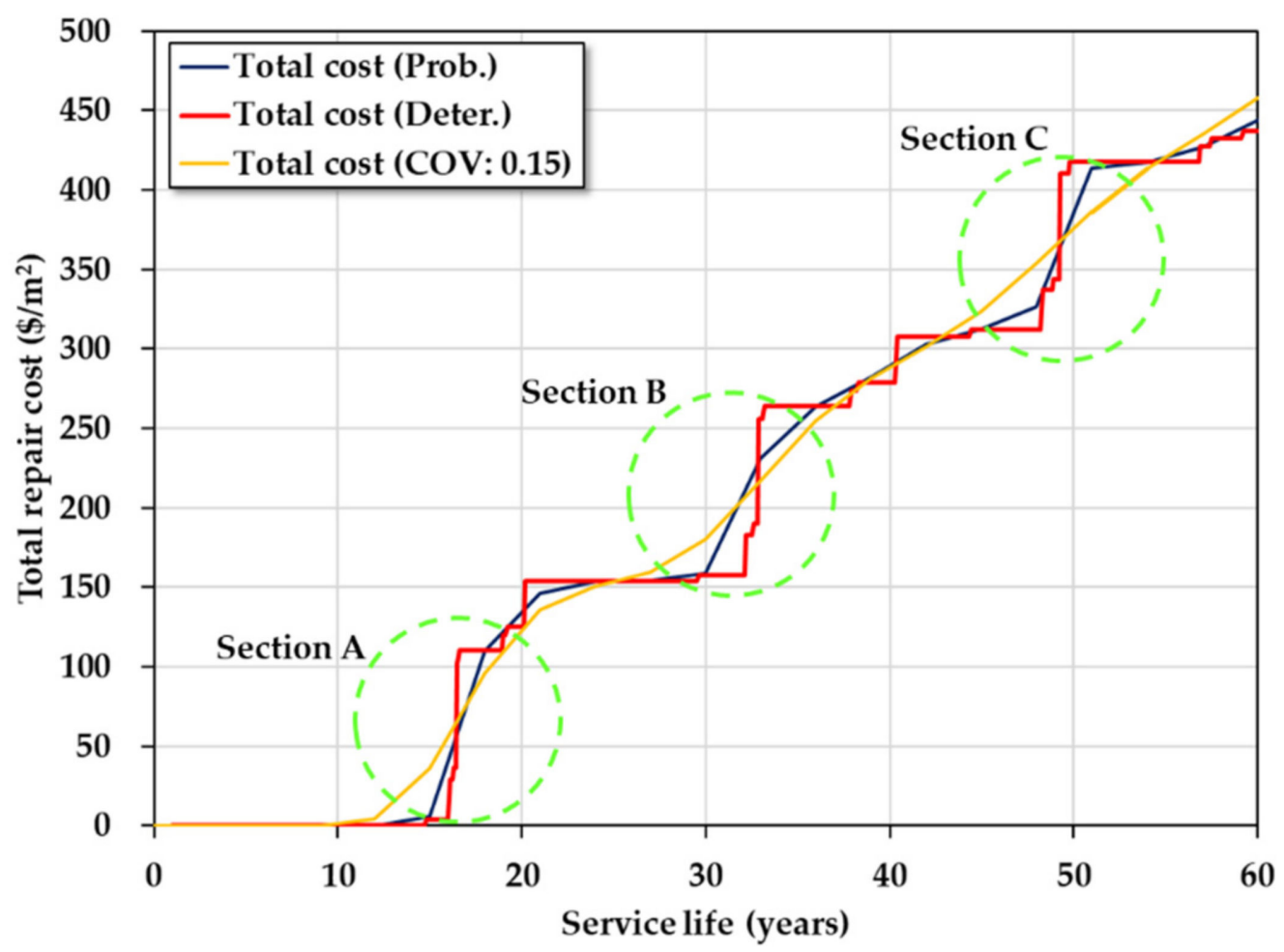

Figure 10. Total repair cost based on deterministic and probabilistic methods (current and COV: 0.15) with extended service life.

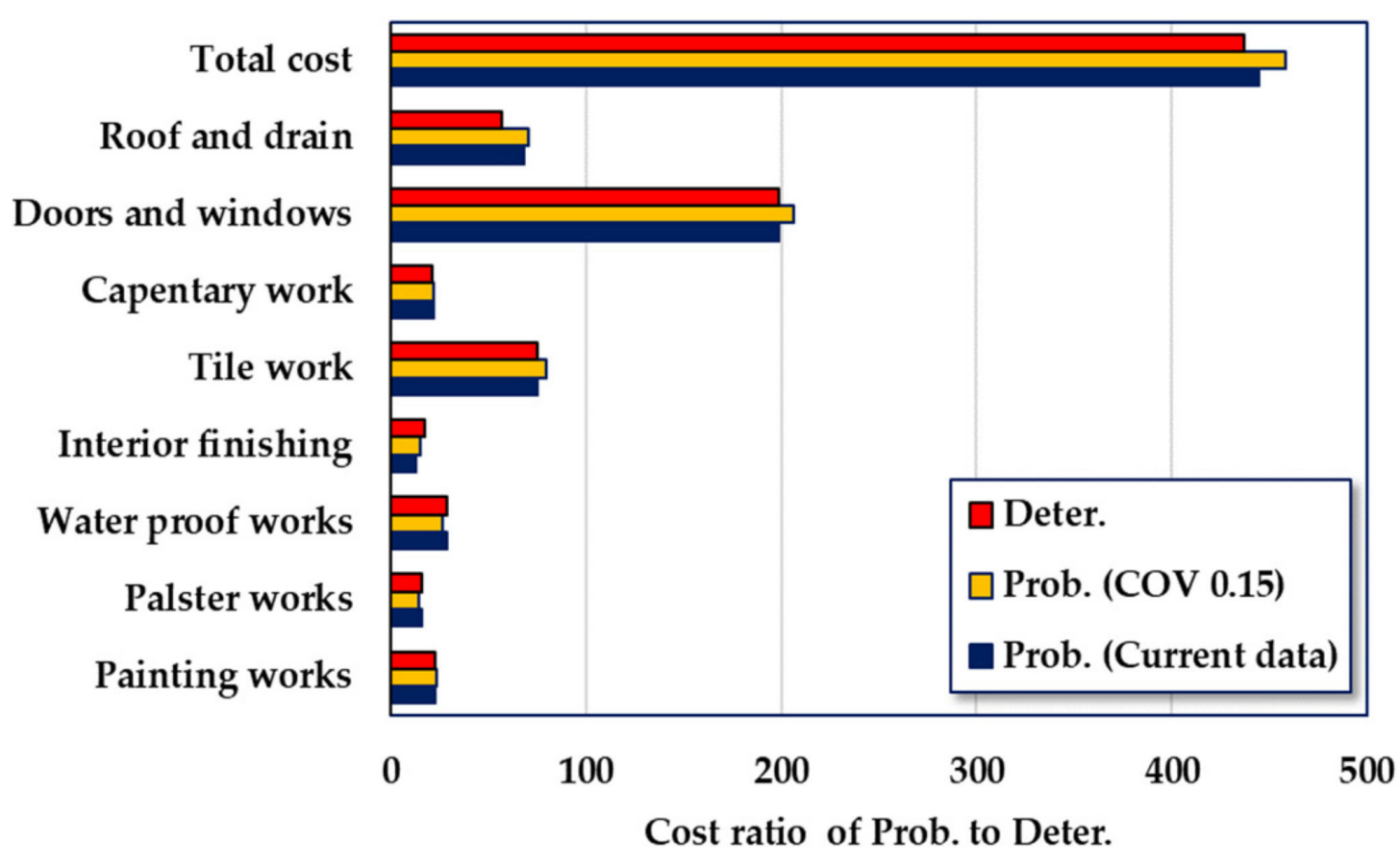

Figure 11. Repair cost per member process after 60 years.

As can be seen from Figure 10, the total repair cost obtained based on the probabilistic method shows a strong tendency of a smooth continuous function as the COV increases, and the time when the repair can be performed most cost-effectively is between $40 \%$ and $50 \%$ of the corresponding service life after the repair timing is determined based on the deterministic method. Based on previous studies $[19,20,27]$, the probabilistic analysis is 
conducted differently from the deterministic method that considers a constant repair cost for the corresponding service life. It can reduce the number of repairs by adjusting the target service life. For Figure 11, the sum of the repair costs of the eight processes was calculated based on the period of usage. Therefore, the deterministic method exhibits a continuous tendency. Between 25 and 33 years, the probabilistic method exhibited a higher repair cost. This is because the COV had a negative effect. Between 33 and 37 years, however, the repair cost obtained based on the probabilistic method was evaluated to be lower because the COV had a positive effect. In this case, when the COV was large, a lower repair cost was calculated. After the target service life of 60 years, the repair cost was evaluated to be $\$ 444.34$ for the probabilistic method with low COV, $\$ 458.33$ for the probabilistic method with a COV of 0.15 , and $\$ 437$ for the deterministic method.

When the repair cost variation over time is analyzed, the process with a high repair cost (door and windows) has a dominant effect. Therefore, changes in the repair cost before and after the service life of the process for doors and windows were compared in sections A, B, and C, and the results are shown in Figure 12. In section A, the deterministic method exhibited the lowest repair cost of $\$ 4.30$, and the probabilistic method with a COV of 0.15 showed the highest repair cost of $\$ 35.80$ before $T_{1}$ (the first service life: 16.41 years). After $T_{1}$; however, a different trend was observed. The deterministic method exhibited the highest cost of $\$ 153.70$, whereas the probabilistic method with a COV of 0.15 exhibited the lowest cost of $\$ 135.80$. In sections $B$ and $C$, the same tendency was also observed for $T_{2}$ (the second service life: 38.32 years) and $T_{3}$ (the third service life: 49.23 years). This is because the magnitude of the COV for the probabilistic method affects the probability of failure before and after the determined service life. While the deterministic method exhibited the lowest repair cost of $\$ 158.10$ and the probabilistic method with a COV of 0.15 showed the highest cost of $\$ 180.10$ before $T_{2}$, the values changed to $\$ 263.90$ and $\$ 255.10$, respectively, after $T_{2}$. The same tendency was observed for $T_{3}$. The repair cost ranged from 311.84 to $\$ 417.60$ for the deterministic method, from 326.3 to $\$ 413.80$ for the probabilistic method in consideration of the current conditions, and from 353.7 to $\$ 386.30$ for the probabilistic method with a COV of 0.15 .

If the skill of the workforce and the characteristics of repair and plaster materials are considered to quantify the repair timing, the distribution of the service life extended for each process can be clearly defined. Based on this, a reasonable probabilistic maintenance method can be applied.

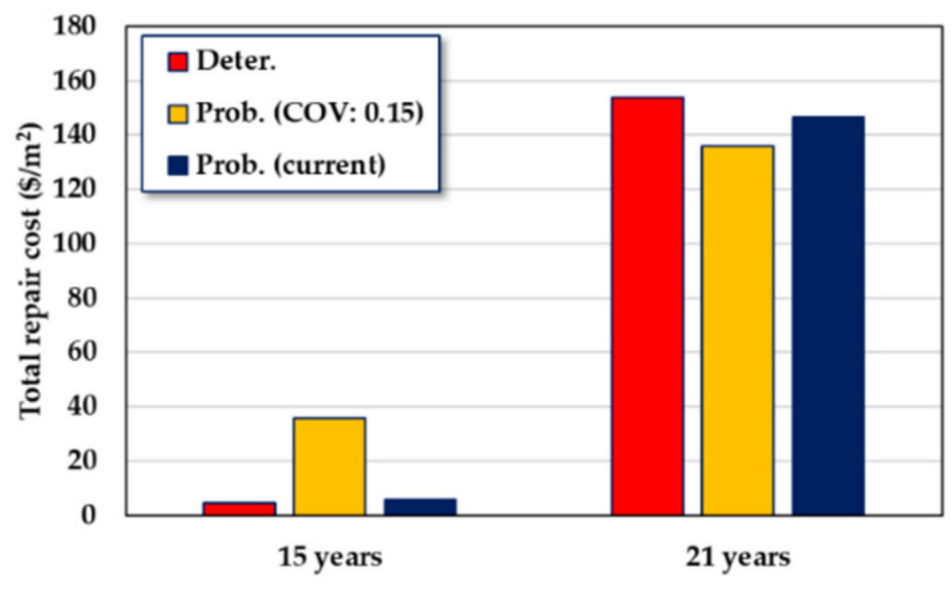

(a) Repair cost before and after $T_{1}$ (windows and doors: 15 and 21 years)

Figure 12. Cont. 


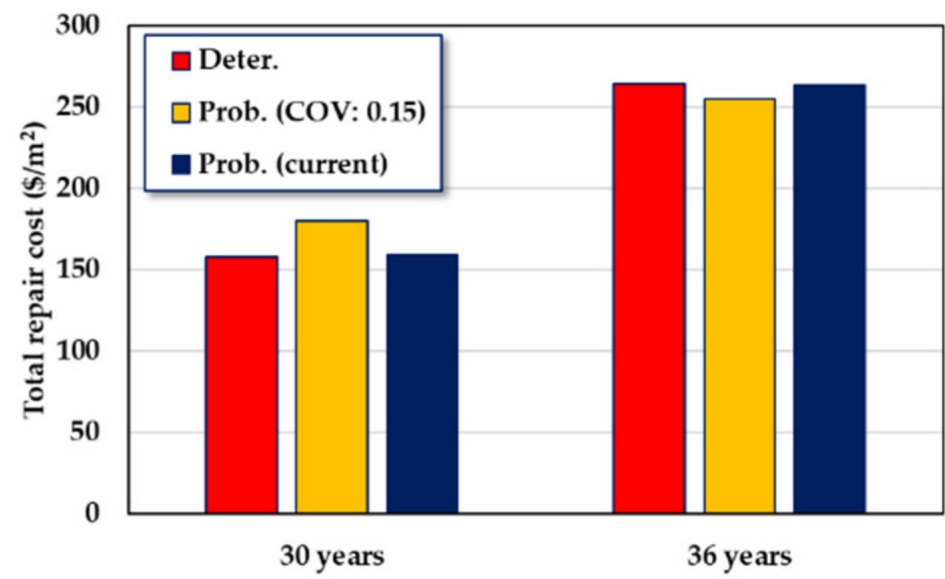

(b) Repair cost before and after $T_{2}$ (windows and doors: 30 and 36 years)

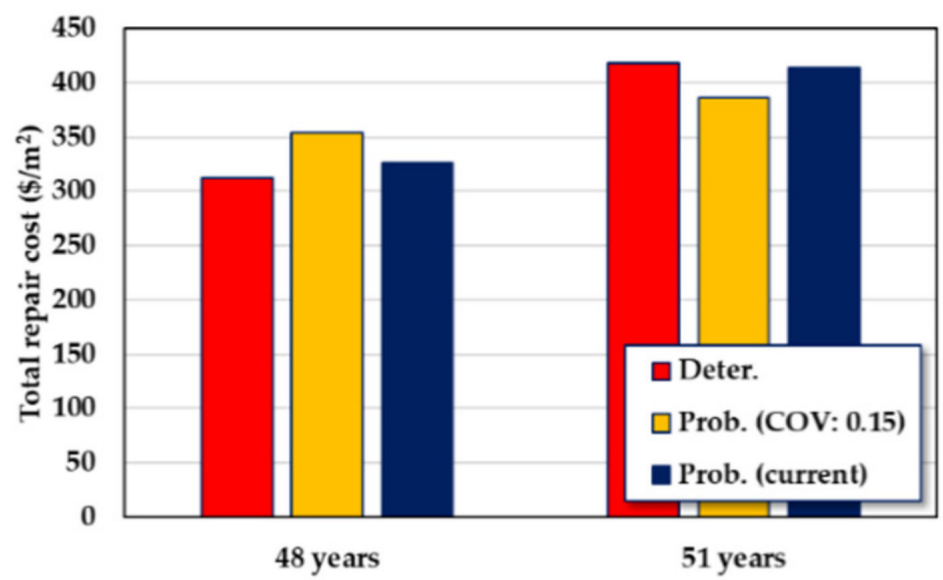

(c) Repair cost before and after $T_{3}$ (windows and doors: 48 and 51 years)

Figure 12. Repair cost variation before and after a major member repair process.

\section{Conclusions}

In this study, the probabilistic measures of the structural members of public houses, derived in previous studies, were quantified, and the repair cost was analyzed by assuming a normal distribution according to the target service life. The proposed probabilistic method can be more useful when extended service life through the repairing process is physically investigated, such as quantification of mean value, COV, and the shape of probability function (log or normal). The conclusions drawn from this study are as follows:

(1) Based on the literature review, it was found that the service life of repair processes for public houses ranged from 14.80 to 20.18 years, and their coefficient of variation $(\mathrm{COV})$ ranged from $1.8 \%$ to $13.8 \%$, indicating a very low level of variation. This is because construction-related works, such as demolition and extensive repairs, were performed at planned specific time points, and there was no significant difference between the repair costs derived from the deterministic and probabilistic methods because of the low variation. After the target service life (60 years), the total repair cost was evaluated to be $\$ 437$ for the deterministic method and $\$ 444$ for the probabilistic method. When establishing a long-term maintenance strategy for a general building structure composed of various members with different service life, the integrated analysis model proposed in this study can be useful for efficient maintenance cost management. 
(2) When the repair cost was evaluated by fixing the COV of each process at 0.15 , the probabilistic method exhibited a higher repair cost for 25-33 years and a lower repair cost for 33-37 years owing to the positive effect of COV. The repair cost was evaluated to be $\$ 444.34$ for the probabilistic method that considered the current conditions for the service life, $\$ 458.33$ for the probabilistic method with a COV of 0.15 , and $\$ 437$ for the deterministic method. The repairing frequency was not significant when it has a low unit repair cost; on the contrary, the repair process with a high-cost had a great influence on the behavior for total maintenance cost.

(3) When changes in repair cost before and after the high-cost repair process (doors and window) that had a significant impact on the total repair cost were analyzed, the deterministic method exhibited the lowest repair cost of $\$ 4.30$, and the probabilistic method with a COV of 0.15 showed the highest repair cost of $\$ 35.80$ before $T_{1}$ (the first service life: 16.41 years). After $T_{1}$, however, a different tendency was observed as the deterministic method exhibited the highest cost of $\$ 153.70$, while the probabilistic method with a COV of 0.15 showed the lowest cost of $\$ 135.80$. The same tendency was also observed for $T_{2}$ and $T_{3}$ because the magnitude of the COV for the probabilistic method affected the variation in the service life. The probabilistic maintenance technique can be effectively used to calculate the total repair cost when the initial repair timing is extended to the largest possible extent, for the process with the highest member-repair-cost (windows and doors) and if the process-related COV is applied. In addition, more economical maintenance repair costs can be achieved by additional actual condition surveys of cases showing different service life and the characteristics of the probability function.

Author Contributions: Conceptualization, S.-J.K. and Y.-H.A.; formal analysis, S.-J.K., Y.-S.Y. and X.-Y.W.; funding acquisition, S.-J.K.; investigation, Y.-H.A. and X.-Y.W.; supervision, S.-J.K.; data curation, S.-J.K., Y.-H.A., Y.-S.Y. and X.-Y.W.; writing-original draft preparation, S.-J.K. and Y.-S.Y.; writing-review and editing, S.-J.K. and Y.-S.Y. All authors have read and agreed to the published version of the manuscript.

Funding: This research was supported by Basic Science Research Program through the National Research Foundation of Korea (NRF), funded by the Ministry of Science, ICT and Future Planning (No. 2015R1A5A1037548) and an NRF grant (NRF-2020R1A2C2009462).

Institutional Review Board Statement: Not applicable.

Informed Consent Statement: Not applicable.

Data Availability Statement: The data presented in this study is not publicly available due to the continuation of research. The data is available on request from the corresponding author.

Conflicts of Interest: The authors declare no conflict of interest.

\section{References}

1. Kwon, S.J. Current trends of durability design and government support in South Korea: Chloride attack. Sustainability 2017, 9, 417. [CrossRef]

2. Thomas, M.D.A.; Bentz, E.C. Life-365TM Service Life Prediction ModelTM and Computer Program for Predicting the Service Life and Life-Cycle Costs of Reinforced Concrete Exposed to Chlorides; SFA: Lovettsville, VA, USA, 2002; pp. 2-28.

3. Lee, S.H.; Ahn, A.H. Analyzing the Long-Term Service Life of MEP Using the Probabilistic Approach in Residential Buildings. Sustainability 2018, 10, 3803. [CrossRef]

4. Lee, H.C.; Kim, Y.S. A Study on the Problem Analysis and Improvements of Long-Term Maintenance for the Permanent Rental Housing in Korea. Korean J. Constr. Eng. Manag. 2005, 6, 169-176.

5. Wang, B.; Xia, X. Optimal maintenance planning for building energy efficiency retrofitting from optimization and control system perspectives. Energy Build. 2015, 96, 299-308. [CrossRef]

6. Frangopol, D.M.; Neves, L.C. Probabilistic Maintenance and Optimization Strategies for Deterioration Civil infrastructures, Progress. In Computational Structures Technology; Topping, B.H.V., Mota Soares, C.A., Eds.; Saxe-Coburg Publications: Stirling, UK, 2004. 
7. Bowles, D.S. Evaluation and Use of Risk Estimates in Dam Safety Decision making. In Proceedings of the United Engineering Foundation Conference on Risk-Based Decision-Making in Water Resources IX, 20-Year Retrospective and Prospective of Risk-Based Decision-Making, Santa Barbara, CA, USA, 15-20 October 2001; ASCE: Reston, VA, USA, 2001.

8. Chan, A.; Keoleian, G.; Gabler, E. Evaluation of lifecycle cost analysis practices used by the Michigan Department of Transportation. J. Transp Eng. 2008, 134, 236-245. [CrossRef]

9. Song, H.W.; Pack, S.W.; Lee, C.H.; Kwon, S.J. Service life prediction of concrete structures under marine environment considering coupled deterioration. Restor. Build. Monuments. 2006, 12, 265-284. [CrossRef]

10. Azhar, S. Building information modeling (BIM): Trends, benefits, risks, and challenges for the AEC industry. Leadersh. Manage. Eng. 2011, 11, 241-252. [CrossRef]

11. Kumar, V.P.; Balasubramanian, M.; Raj, S.J. Robotics in construction industry. Ind. J. Sci Tech. 2016, 9, 1-12.

12. Waly, A.F.; Thabet, W.Y. A virtual construction environment for preconstruction planning. Autom. Constr. 2003, 12, 139-154. [CrossRef]

13. Dave, B.; Kubler, S.; Främling, K.; Koskela, L. Opportunities for enhanced lean construction management using Internet of Things standards. Autom. Constr. 2016, 61, 86-97. [CrossRef]

14. Park, S.Y.; Ahn, Y.H.; Lee, S.H. Analyzing the Finishing Works Service Life Pattern of Public Housing in South Korea by Probabilistic Approach. Sustainability 2018, 10, 4469. [CrossRef]

15. Mulubrhan, F.; Mokhtar, A.A.; Muhammad, M. Integrating reliability analysis in life cycle cost estimation of heat exchanger and pump. Adv. Mater. Res. 2014, 903, 408-413. [CrossRef]

16. Nasir, M.; Chong, H.Y.; Osman, S. Probabilistic life cycle cost model for repairable system. IOP Conf. Series Mater. Sci. Eng. 2015, 78, 012027. [CrossRef]

17. Rahman, S.; Vanier, D.J. Life cycle cost analysis as a decision support tool for managing municipal infrastructure. In Proceedings of the CIB Triennial, CIB 2004 Triennial Congress, Toronto, ON, Canada, 2-7 May 2004; pp. 1-11.

18. Salem, O.; Abourizk, S.; Ariaratnam, S. Risk-based life-cycle costing of infrastructure rehabilitation and construction alternatives. J. Infrastruct. Syst. 2003, 9, 6-15. [CrossRef]

19. Jung, S.H.; Yang, H.M.; Yang, K.H.; Kwon, S.J. Maintenance for Repaired RC Column Exposed to Chloride Attack Based on Probability Distribution of Service Life. Int. J. Concr. Struct. Mater. 2018, 12, 1-9. [CrossRef]

20. Kwon, S.J. Repair cost optimization for maintenance of RC structure subjected to carbonation. Int. J. Sustain. Build. Techn. Urban. Dev. 2017, 8, 274-284.

21. Lee, H.S.; Kwon, S.J. Probabilistic analysis of repairing cost considering random variables of durability design parameters for chloride attack. J. Korea Inst. Struct. Maint. Inspect. 2018, 22, 28-32.

22. Yoon, Y.S.; Kwon, S.J. Repair Cost Analysis for Chloride Ingress on RC Wall Considering Log and Normal Distribution of Service Life. J. Korea Inst. Struct. Maint. Inspect. 2019, 23, 10-19.

23. Forcada, N.; Macarulla, M.; Gangolells, M.; Casals, M. Handover defects: Comparison of Construction and Post-handover housing defects. J. Build. Res. Inf. 2016, 44, 279-288. [CrossRef]

24. Roh, S.J.; Tae, S.H.; Suk, S.J.; Ford, G. Evaluating the Embodied Environmental Impacts of Major Building tasks and Materials of Apartment buildings in Korea. Renew. Sustain. Energy Rev. 2017, 73, 135-144. [CrossRef]

25. Total Information Service Corporation. TOTAL-LCC-Technical Manual, ver.1.1, 2nd ed.; Total Information Service Corp: Tokyo, Japan, 2010.

26. KICT. Standard Market Price for Construction Works in the Second Half of 2019; Korea Institute of Civil Engineering and Building Technology: Goyang-si, Korea, 2020.

27. Yang, K.H.; Lim, H.S.; Kwon, S.J.; Kim, J.H. Repair cost estimation techniques for reinforced concrete structures located at the seashore: Considering various probabilistic service life functions and actual mix proportions. Constr. Build. Mater. 2020, 256, 119469. [CrossRef] 